Western University

Scholarship@Western

Aboriginal Policy Research Consortium International (APRCi)

2013

\title{
The health and well-being of Indigenous drug and alcohol workers: Results from a national Australian survey
}

Ann M. Roche

Vinita Duraisingam

Allan Trifonoff

Amanda Tovell

Follow this and additional works at: https://ir.lib.uwo.ca/aprci

Part of the Substance Abuse and Addiction Commons

Citation of this paper:

Roche, Ann M.; Duraisingam, Vinita; Trifonoff, Allan; and Tovell, Amanda, "The health and well-being of Indigenous drug and alcohol workers: Results from a national Australian survey" (2013). Aboriginal Policy Research Consortium International (APRCi). 325.

https://ir.lib.uwo.ca/aprci/325 


\title{
The health and well-being of Indigenous drug and alcohol workers: Results from a national Australian survey
}

\author{
Ann M. Roche, Ph.D. * Vinita Duraisingam, Master Org. Psych., \\ Allan Trifonoff, Grad. Dip. Leg. Stud., Amanda Tovell, Master Soc. Work \\ National Centre for Education and Training on Addiction, Flinders University, South Australia
}

\section{A R T I C L E I N F O}

\section{Article history:}

Received 1 July 2011

Received in revised form 25 January 2012

Accepted 31 January 2012

\section{Keywords:}

Indigenous

Alcohol

Drugs

Drug and alcohol workers

Stress

Job satisfaction

Turnover intentions

Workforce development

Well-being

Retention

\begin{abstract}
A B S T R A C T
The increasing demand for alcohol and other drug (AOD) treatment services among the Australian Indigenous population, complex organisational challenges and limitations, and high unemployment rates are likely to negatively impact Indigenous AOD workers' health and well-being. Building the capacity of Indigenous AOD workers is vital, as they play a crucial role in the delivery of treatment services and offer essential support to their communities. A national online survey was conducted to examine organisational, workplace and individual factors that might contribute to levels of stress and well-being among workers who provide services to Indigenous clients. A total of 294 eligible surveys were completed; 184 (63\%) from Indigenous and 108 (37\%) from non-Indigenous AOD workers. Multiple regression models were conducted to assess the significant predictors of mental health and well-being, job satisfaction, emotional exhaustion, and turnover intention. Indigenous AOD workers typically experienced above average levels of job satisfaction and relatively low levels of emotional exhaustion. However, 1 in 10 reported high levels of emotional exhaustion, a key predictor of turnover intention. Indigenous workers also experienced significantly lower levels of mental health and well-being and greater work/family imbalance, which was a significant contributor to emotional exhaustion. The findings highlight the importance of implementing workforce development strategies that focus on achieving culturally appropriate, equitable and supportive organisational conditions for Indigenous AOD workers. Preventing or managing levels of stress, ensuring adequate and equitable salaries and benefits, and providing more opportunities for career and personal growth may increase job satisfaction and reduce turnover intention among Indigenous workers in the drug and alcohol field.
\end{abstract}

Crown Copyright @ 2013 Published by Elsevier Inc. All rights reserved.

\section{Introduction}

\subsection{Alcohol and other drug use in the Australian Indigenous population}

Indigenous Australians, that is Aboriginal and/or Torres Strait Islander peoples who are descendants of the original inhabitants of Australia, experience many socioeconomic disadvantages and inequalities, similar to those experienced by Native Americans in the US. Recent surveys estimate that Indigenous Australians are twice as likely to have high or very high levels of psychological distress compared with the community overall (AIHW, 2010). Prevalence of harmful alcohol and illicit substance use is almost double that of nonIndigenous Australians (AIHW, 2008; Wilson, Stearne, Gray, \& Saggers, 2010). These behaviours are associated with increased socioeconomic disadvantage, higher incidence of mental disorders, family breakdown, violence, and higher rates of poorer physical

\footnotetext{
* Corresponding author. National Centre for Education and Training on Addiction (NCETA), Flinders University, GPO Box 2100, Adelaide SA 5001, South Australia. Tel: +6108 8201 7535; fax: +61 0882017550 .

E-mail address: ann.roche@flinders.edu.au (A.M. Roche).
}

health, hospitalization and mortality compared with the nonIndigenous population resulting in a heavy impost on the health and community care treatment system and its workforce.

The Australian drug treatment system comprises a diverse range of organisations that straddle the government, not-for-profit (or nongovernment) and private sectors. The systems and structures within which services operate vary considerably across sectors, jurisdictions and individual agencies (Roche \& Pidd, 2010). Treatment approaches also vary, for example, government organisations are more likely to adopt a harm minimisation approach while non-government and private organisations/agencies are more likely to utilise an abstinenceoriented approach and commonly provided treatment services include counselling, pharmacotherapy, outpatient and inpatient rehabilitation/withdrawal and therapeutic communities (Roche \& Pidd, 2010).

\subsection{Health and well-being of drug and alcohol workers}

Drug and alcohol workers face many distinct challenges that may affect their capacity, responsiveness and sustainability. In addition to a growing demand for services, the drug and alcohol field experiences difficulties in recruiting and retaining qualified staff, particularly in 
rural and remote areas (Duraisingam, Pidd, Roche, \& O'Connor, 2006; Pitts, 2001; Roche \& Pidd, 2010; Wolinski, O'Neill, Roche, Freeman, \& Donald, 2003). Organisational and work-related factors such as excessive job demands (e.g., heavy workloads, client pressure, complexity of clients' problems) and lack of job resources (e.g., lack of job autonomy, limited workplace support, inadequate salaries) may contribute to increased levels of stress and burnout and jeopardise worker well-being (Duraisingam et al., 2006; Duraisingam, Roche, Pidd, Zoontjens, \& Pollard, 2007). A recent national survey found that almost one in five frontline Australian drug and alcohol workers experience high stress levels, contributing to lower job satisfaction, and increased likelihood of leaving their job (Duraisingam et al., 2006). In addition, studies of frontline substance misuse workers in the UK and US have found high levels of psychological morbidity and burnout, suggesting greater vulnerability for these workers than other health professionals and a propensity for high turnover (Knudsen, Ducharme, \& Roman, 2006, 2009; Oyefeso, Clancy, \& Farmer, 2008).

\subsection{Challenges faced by Indigenous AOD workers}

A subset of the drug and alcohol workforce is the Indigenous alcohol and other drug (AOD) workers. The high prevalence of drug- and alcohol-related problems and a strong preference to be seen by a member of their own community, who understands their circumstances and cultural needs (Guerin, Guerin, \& Seamann, 2011; Taylor \& Guerin, 2010), mean that Indigenous AOD workers play a critical role in the delivery of treatment services and offer essential support to their communities. The specialist services supplied are not just clinical. These workers provide a multitude of valued roles to local Indigenous and non-Indigenous communities and health organisations, reflecting their unique understanding of local Indigenous culture, history and language as well as being key community members. They often act as cultural brokers and have the ability to understand and interpret "mainstream" issues for their Indigenous community (Panaretto \& Wenitong, 2006).

Indigenous AOD workers include Aboriginal/Islander health workers, Aboriginal liaison officers, Indigenous doctors, nurses, drug and alcohol clinicians, community health workers and mobile patrol staff. The role of Aboriginal health workers is not consistent across jurisdictions and organisations, and it is a position title applied to workers with differing levels of training and educational qualifications who may undertake clinical, transport, liaison, or advocacy functions (Australian Government Department of Health and Ageing, 2008; Genat et al., 2006). They may act as health educators, mental health and AOD counsellors, community health action agents, and providers of basic personal medical care (Genat et al., 2006). AOD qualifications for Indigenous workers are a relatively recent development (Roche, Duraisingam, Wang, \& Tovell, 2008), and responding to AOD issues often falls to workers such as Aboriginal health workers who possess general health qualifications.

Although some studies have examined the efficacy of Indigenousspecific drug and alcohol programs (Strempel, Saggers, Gray, \& Stearne, 2004), and important Indigenous workforce development projects have been undertaken, there have been few investigations into the well-being of Indigenous AOD workers or the capacity of Indigenous services to attract, support and retain workers. There is also limited research on Indigenous drug and alcohol issues including workers' experiences of dealing with clients with drug and alcohol problems, and its impact on them as workers.

Anecdotal evidence indicates that Indigenous AOD workers experience a greater range of work-related stressors and pressures than their non-Indigenous counterparts. There are comparatively few Indigenous people employed in the health and human services fields relative to the size of the Indigenous population. Indigenous health professionals comprised only $1 \%$ of the total health workforce in 2006 but approximately 3\% of the total population (AIHW, 2009a, 2009b). There is a large shortfall in the number of available Indigenous health care workers. Combined with high community need this compounds the pressure on Indigenous AOD workers (Gray, Saggers, Atkinson, \& Strempel, 2004).

In addition to low labour participation rates, issues specific to Indigenous AOD workers include racism; lack of culturally appropriate support and understanding; working in remote rural communities; and the challenge of setting appropriate boundaries (Roche \& Pidd, 2010). A lack of clearly defined roles and limited human and other resources place further demands on these workers (Roche \& Pidd, 2010). Moreover, the multitude of disadvantages and inequalities that Indigenous Australians face contribute to complicated client presentations and the load carried by Indigenous workers in dealing with clients with complex needs. Constantly dealing with traumatised clients and the associated problems of unemployment, poor education, substance use and violence represent a further threat to the well-being of Indigenous health staff (Panaretto \& Wenitong, 2006).

Previous research has highlighted the plethora of issues faced by Australian Indigenous human service workers (Stanley, Tomison, \& Pocock, 2003). Because Indigenous workers often live and work within the same community, conflicts of interest and confidentiality issues may arise with clients who are also family/clan members. Culturally appropriate worker training and support are also often limited (Stanley et al., 2003). From a workforce development perspective, the ability to attract and maintain skilled, qualified, and culturally competent Indigenous and non-Indigenous staff is an important element in the success of Indigenous drug and alcohol programs (Strempel et al., 2004). Worker well-being has a substantial impact on the capacity and sustainability of drug and alcohol agencies to respond effectively to drug- and alcohol-related issues in the community.

Within the general health care setting, problems arise in incorporating evidence-based changes to clinical practice because of lack of time and expertise by individual workers, inefficient systems and lack of organisational level resources, and alternative preferences by clients (Shakeshaft, Clifford, \& Shakeshaft, 2010). Among Indigenous AOD organisations these problems are further amplified and constitute significant challenges for workers in ensuring the provision of effective and efficient care for clients.

In summary, Indigenous AOD workers are not only confronted by the significant challenges experienced by the drug and alcohol workforce in general (i.e., high job demands, complex client needs, and inadequate resources) but are also faced with organisational and systemic issues such as intermittent and uncertain funding, comparatively low salaries and limited career pathways, stigma and racismall of which may have an impact on their health and well-being.

\subsection{A national survey}

To assess the nature and extent of these challenges, a national survey was conducted of Indigenous and non-Indigenous workers from drug and alcohol organisations that provide services to the Indigenous population across Australia. The survey was one component of a more extensive project and the first study of its kind in Australia. The project was conducted to examine potential contributory factors, at the organisational, workplace and individual level, to stress and well-being among workers from AOD organisations that mainly provide services to Indigenous people. This paper focuses on the quantitative findings of the national survey. It was hypothesized that differential findings would be identified for Indigenous AOD workers compared with their non-Indigenous counterparts.

\section{Materials and methods}

\subsection{Sample and study design}

The survey targeted Indigenous and non-Indigenous AOD specialist and generic health workers in government, non-government, or 
community-controlled organisations across Australia who primarily worked with Indigenous clients. Ethics approval was obtained from Flinders University Social and Behavioural Research Ethics Committee. Invitations to participate were distributed via drug and alcohol online listserves and newsletters with periodic reminders to increase the sample size. The survey took approximately 20 minutes to complete, confidentiality and anonymity was assured and hard copies were available if preferred.

\subsection{Measures}

\subsubsection{Demographics}

The questionnaire included demographic variables such as age, gender, ethnicity, country of birth, geographical location, educational qualifications and employment details (i.e., job role, work arrangements, duration of employment, salary range, type of organisation, type of Indigenous-specific services provided).

\subsubsection{Work outcomes}

Work-related outcomes measured included turnover intention, emotional exhaustion, mental health and well-being, and job satisfaction. Reliability coefficients for each work outcome scale are listed in Table 3.

A four-item scale developed by O'Driscoll and Beehr (1994) was used to measure intention to quit (e.g., "I have thought about leaving my job."). Responses ranged from 1 (strongly disagree) to 5 (strongly agree). Scores on all items were tallied to obtain a total turnover intention score. Higher scores denoted greater turnover intention. Respondents also nominated important retention strategies.

Nine items measuring emotional exhaustion were selected from the Maslach Burnout Inventory, a well-established scale that measures burnout (Maslach, Jackson, \& Leiter, 1996). While the scale measures three dimensions of burnout (emotional exhaustion, depersonalisation, and reduced personal accomplishment), emotional exhaustion is the strongest factor in the measurement of burnout (Maslach, Schaufeli, \& Leiter, 2001). For conciseness, only the emotional exhaustion subscale was used. The scale measures physical and emotional fatigue arising from work in general and working with clients (e.g., "I feel emotionally drained from my work."). Responses for each item ranged from 0 (never) to 6 (everyday). Scores on all nine items were summed to obtain a total score. High scores were indicative of symptoms of burnout.

Six questions were taken from the Indigenous Risk Impact Screen, a 13-item screening instrument that assesses drug and alcohol use and mental health risk (Schlesinger, Ober, McCarthy, Watson, \& Seinen, 2007). The screening tool has demonstrated reliability and validity with Indigenous populations. The six questions assessed mental health risk specifically (e.g., "How often do you feel nervous or scared?"). Responses ranged from 1 (most days/everyday) to 3 (never/hardly ever). Scores were tallied to give a total score. Higher scores reflected positive mental health and well-being.

Two items were taken from a scale developed by Price and Mueller (1981) to measure job satisfaction (e.g., "I find real enjoyment in my job."). Responses ranged from 1 (strongly disagree) to 5 (strongly agree). High scores reflected high levels of job satisfaction. Respondents were also asked about aspects of work that gave them satisfaction.

\subsubsection{Workplace factors}

Workplace factors measured included client pressure, family/work imbalance, work/family imbalance, experience of racism, workload, extent of positive cultural practices, co-worker support, and physical work environment. Reliability coefficients (Cronbach's alpha) for each work factor scale are listed in Table 3.

To measure the extent of pressure experienced by a variety of different client presentations, 10 items were adapted from the Addiction Employee Stress Scale (Farmer, Clancy, Oyefeso, \& Rassool,
2002). For each client presentation (e.g., poly-drug using clients), responses ranged from 1 (no pressure) to 5 (extreme pressure). Scores were added to obtain a total client pressure score. Higher scores denoted greater client pressure.

Five questions were adapted from the Australian Work and Life Index to measure the extent of work affecting personal life (work imbalance) and personal life affecting work (family imbalance) (Pocock, Williams, \& Skinner, 2007). Three questions measured work imbalance (e.g., "How often does your work interfere with your responsibilities or activities outside work?") and two questions measured family imbalance (e.g., "How often does your personal life interfere with your responsibilities or activities at work?"). A five-item response scale was used that ranged from 1 (never) to 5 (almost always).

Four items were developed to measure participants' experience of racism in the workplace (e.g., "As a worker, I experience racism from co-workers."). Responses ranged from 1 (never) to 5 (all of the time). A total score was obtained. Higher scores equated to a higher level of racism experienced in the workplace.

Seven items were developed to measure the extent of positive cultural practices within participants' organisations. Items were based on the Cultural Respect Framework for Aboriginal and Torres Strait Islander Health (AHMAC, 2004), for example, "Indigenous workers within my organisation have a culturally supportive work environment." Responses were based on a five-point agreement scale (i.e., 1strongly disagree to 5-strongly agree). Higher scores denoted a greater adoption of positive cultural practices.

Nine items were selected from the Perceived Co-worker Support Scale developed by Ladd and Henry (2000) to measure co-worker support (e.g., "My co-workers really care about my well-being."). For each item, participants indicated their level of agreement on a fivepoint response scale (1-strongly disagree to 5-strongly agree). Scores for all items were added to obtain a total co-worker support score. High scores reflected higher levels of co-worker support.

Two items measured perceptions of the work environment as a safe and pleasant workplace (e.g., "I work in a safe working environment."). Responses ranged from 1 (strongly disagree) to 5 (strongly agree). Scores for each item were summed to provide a total physical work environment score.

\subsection{Data analyses}

All analyses were conducted using SPSS v15. Descriptive statistics were used to summarise key responses and demographic characteristics of the sample. Comparisons of mean scores between Indigenous and non-Indigenous respondents were conducted via t-tests. Because preliminary analyses found significant differences between the Indigenous and non-Indigenous respondents these data were analysed and reported separately. Data were checked for normality, multicolinearity and outliers prior to running multiple regressions. Standard multiple regressions were performed to examine the relationship between work factors and each work-related outcome (i.e., emotional exhaustion, mental health and well-being, and job satisfaction). A hierarchical multiple regression was conducted for turnover intention. Job satisfaction, mental health and well-being, and emotional exhaustion were theorised to be central predictors of workers' intentions to leave their organisation. Hence, these factors were entered first, and the work factors were entered as the second step in the analysis to examine their additional contribution.

\section{Results}

\subsection{Demographic characteristics}

A total of 294 respondents (184 Indigenous, 108 non-Indigenous, and 2 unknown) completed the survey. The key demographic characteristics of respondents are listed in Table 1. Most respondents 
Table 1

Key demographic characteristics of survey respondents.

\begin{tabular}{|c|c|c|c|c|c|c|c|}
\hline \multirow[t]{2}{*}{ Demographic } & & \multicolumn{2}{|c|}{ Indigenous } & \multicolumn{2}{|c|}{ Non-Indigenous } & \multicolumn{2}{|l|}{ Total } \\
\hline & & $\%$ & $n$ & $\%$ & $n$ & $\%$ & $n$ \\
\hline \multirow[t]{3}{*}{ Country of birth } & Australia & 97 & 178 & 73 & 79 & 88 & 257 \\
\hline & Other & 3 & 5 & 27 & 29 & 12 & 34 \\
\hline & Total & 100 & 183 & 100 & 108 & 100 & 291 \\
\hline \multirow[t]{3}{*}{ Gender } & Male & 29 & 51 & 31 & 33 & 30 & 84 \\
\hline & Female & 71 & 126 & 69 & 74 & 70 & 200 \\
\hline & Total & 100 & 177 & 100 & 107 & 100 & 284 \\
\hline \multirow[t]{7}{*}{ Age range } & $\leq 19$ years & 1 & 2 & 0 & 0 & 1 & 2 \\
\hline & 20-29 years & 11 & 20 & 8 & 9 & 10 & 29 \\
\hline & 30-39 years & 30 & 55 & 18 & 19 & 26 & 74 \\
\hline & 40-49 years & 35 & 64 & 37 & 40 & 36 & 104 \\
\hline & 50-59 years & 18 & 32 & 31 & 33 & 22 & 65 \\
\hline & $\geq 60$ years & 5 & 9 & 7 & 7 & 5 & 16 \\
\hline & Total & 100 & 182 & 100 & 108 & 100 & 290 \\
\hline \multirow[t]{2}{*}{ Location $^{\mathrm{a}}$} & Metropolitan & 41 & 76 & 26 & 28 & 36 & 104 \\
\hline & $\begin{array}{l}\text { Non-metropolitan } \\
\text { (includes rural/remote outreach) }\end{array}$ & 96 & 177 & 76 & 82 & 91 & 259 \\
\hline \multirow{6}{*}{$\begin{array}{l}\text { Length of service } \\
\text { (organisational tenure) }\end{array}$} & $<1$ year & 24 & 44 & 15 & 16 & 21 & 60 \\
\hline & $1-2$ years & 29 & 53 & 23 & 25 & 27 & 78 \\
\hline & $3-5$ years & 19 & 35 & 30 & 32 & 23 & 67 \\
\hline & $6-10$ years & 18 & 32 & 21 & 22 & 19 & 54 \\
\hline & $>10$ years & 10 & 16 & 11 & 12 & 10 & 28 \\
\hline & Total & 100 & 180 & 100 & 107 & 100 & 287 \\
\hline \multirow{3}{*}{$\begin{array}{l}\text { Dependents } \\
\text { (children, parents) }\end{array}$} & Yes & 64 & 114 & 48 & 51 & 58 & 165 \\
\hline & No & 36 & 65 & 52 & 56 & 42 & 121 \\
\hline & Total & 100 & 179 & 100 & 107 & 100 & 286 \\
\hline
\end{tabular}

a Some respondents worked in more than one area.

were Indigenous (63\%), female (70\%), born in Australia (88\%), aged between 30 and 49 years (62\%), and worked in non-metropolitan areas (91\%). Nearly half (48\%) had been employed in their current organisation for 2 years or less. Nearly a quarter (24\%) of Indigenous respondents had obtained a university degree (undergraduate or postgraduate) as their highest qualification whereas $57 \%$ of nonIndigenous respondents had a university degree.

Indigenous respondents were younger than non-Indigenous respondents $(\chi 2(4)=10.122, p<.05)$. Most Indigenous respondents (65\%, $n=118$ ) were $30-49$ years old; non-Indigenous respondents were $40-59$ years $(68 \%, n=73)$. There was a higher proportion of older non-Indigenous respondents $(31 \%, n=33)$ aged $50-59$ years compared with similarly aged Indigenous workers $(18 \%, n=33)$. Proportionally more Indigenous respondents had dependents than non-Indigenous respondents $(\chi 2(1)=7.045, p<.01)$. Indigenous respondents were mainly Aboriginal/Islander health workers (18\%, $n=25)$ and AOD workers $(14 \%, n=25)$. Non-Indigenous respondents were mainly nurses $(27 \%, n=29)$ and AOD workers $(23 \%, n=25)$.

\subsection{Work conditions}

Respondents' working conditions are presented in Table 2. Fewer Indigenous $(65 \%, n=108)$ than non-Indigenous $(75 \%, n=71)$ respondents were in permanent positions. About half the total respondents (48\%, $n=124$ ) worked between 21 and 38 hours, and $45 \%$ worked more than 38 hours per week $(n=119)$. Threequarters worked unpaid overtime (74\%, $n=195)$, and $31 \%$ ( $n=78$ ) worked more than 12 hours unpaid overtime a month.

Indigenous respondents had significantly lower salaries compared with non-Indigenous respondents $(\chi 2(5)=23.06, p<.001)$. NonIndigenous respondents were more than twice as likely as Indigenous respondents to earn more than $\$ 60,000$ per annum. To examine factors influencing salary disparity, selected demographic variables were regressed on: salary, occupation, age, and length of service, together with Indigenous versus non-Indigenous status. After controlling for these variables, Indigenous status remained a significant predictor of salary $(B=.14, p<.05)$. Age also predicted salary, with older workers more likely to receive a higher wage than younger workers $(B=.23, p<.001)$. Aboriginal health workers were also significantly more likely to have lower wages than other occupational groups $(B=-.20, p<.01)$.

\subsection{Workplace factors and outcomes}

Table 3 presents the mean scores for key work outcomes and work factors for Indigenous and non-Indigenous respondents. Respondents were generally positive about their work environment and their organisation's cultural practices in regard to Indigenous issues (e.g., culturally supportive working environment, implementation of cultural competency standards). Mean scores for client pressure and workload were above the scale midpoint. For Indigenous workers, greatest pressure was from demanding clients, manipulative clients, and clients with alcohol-related problems. For non-Indigenous workers, greatest pressure was from manipulative clients, poly-drug using clients, and demanding clients. Female non-Indigenous workers $(M=3.30)$ obtained significantly higher mean scores on workload compared with their male counterparts $(M=2.82)(t(92)=-2.26$, $p=.026)$. Indigenous respondents reported poorer work/life balance than non-Indigenous respondents, and were more likely to report that work affected their home life (work imbalance) and that home life affected their work (family imbalance).

For key work outcomes, overall job satisfaction levels were high, while emotional exhaustion, mental health and well-being, and turnover intention scores were moderate (around the midpoint). Indigenous respondents' mean score $(M=2.16)$ for mental health and well-being was significantly lower than that of non-Indigenous respondents' $(M=2.41)(t(278)=-4.93, p<.001)$. A significant association was found between having dependents and better mental health and well-being for non-Indigenous respondents only $(t(100)=2.3$, $p=.026)$. Eleven percent of Indigenous respondents and $6 \%$ of nonIndigenous respondents obtained high scores in emotional exhaustion. Female Indigenous respondents obtained significantly higher average 
Table 2

Working conditions for respondents.

\begin{tabular}{|c|c|c|c|c|c|c|c|}
\hline \multirow[t]{2}{*}{ Work conditions } & & \multicolumn{2}{|c|}{ Indigenous } & \multicolumn{2}{|c|}{ Non-Indigenous } & \multicolumn{2}{|c|}{ Total } \\
\hline & & $n$ & $\%$ & $n$ & $\%$ & $n$ & $\%$ \\
\hline \multirow[t]{6}{*}{ Current work arrangements } & Permanent & 108 & 65 & 71 & 75 & 179 & 68 \\
\hline & Contract & 31 & 19 & 18 & 19 & 49 & 19 \\
\hline & Casual & 10 & 6 & 2 & 2 & 12 & 5 \\
\hline & Other & 14 & 8 & 4 & 4 & 18 & 7 \\
\hline & Unsure & 4 & 2 & 0 & 0 & 4 & 2 \\
\hline & Total & 167 & 100 & 95 & 100 & 262 & 100 \\
\hline \multirow[t]{6}{*}{ Hours of work per week } & $\leq 8$ hours & 8 & 5 & 0 & 0 & 8 & 3 \\
\hline & 9-20 hours & 7 & 4 & 3 & 3 & 10 & 4 \\
\hline & 21-38 hours & 78 & 47 & 46 & 48 & 124 & 48 \\
\hline & 39-50 hours & 61 & 37 & 41 & 43 & 102 & 39 \\
\hline & $>50$ hours & 12 & 7 & 5 & 5 & 17 & 6 \\
\hline & Total & 166 & 100 & 95 & 100 & 261 & 100 \\
\hline \multirow[t]{7}{*}{ Unpaid overtime per month } & None & 47 & 28 & 20 & 21 & 67 & 26 \\
\hline & 1-12 hours & 74 & 44 & 43 & 45 & 117 & 45 \\
\hline & $13-40$ hours & 33 & 20 & 26 & 27 & 59 & 23 \\
\hline & 41-64 hours & 9 & 5 & 3 & 3 & 12 & 5 \\
\hline & $65-80$ hours & 1 & 1 & 2 & 2 & 3 & 1 \\
\hline & $>80$ hours & 3 & 2 & 1 & 1 & 4 & 2 \\
\hline & Total & 167 & 100 & 95 & 100 & 262 & 100 \\
\hline \multirow[t]{8}{*}{ Current annual salary } & $<\$ 20 \mathrm{k}$ & 2 & 1 & 2 & 2 & 4 & 2 \\
\hline & $\$ 20 \mathrm{k}-\$ 30 \mathrm{k}$ & 12 & 7 & 1 & 1 & 13 & 5 \\
\hline & $\$ 30 \mathrm{k}-\$ 40 \mathrm{k}$ & 36 & 22 & 9 & 9 & 45 & 17 \\
\hline & $\$ 40 \mathrm{k}-\$ 50 \mathrm{k}$ & 42 & 25 & 19 & 20 & 61 & 24 \\
\hline & $\$ 50 \mathrm{k}-\$ 60 \mathrm{k}$ & 42 & 25 & 24 & 25 & 66 & 25 \\
\hline & $>\$ 60 \mathrm{k}$ & 31 & 19 & 40 & 42 & 71 & 27 \\
\hline & $<\$ 20 \mathrm{k}$ & 2 & 1 & 2 & 2 & 4 & 2 \\
\hline & Total & 165 & 100 & 95 & 100 & 260 & 100 \\
\hline
\end{tabular}

turnover intention scores than their male counterparts (2.77 vs. 2.40) $(t(155)=-2.36, p=.019)$.

\subsection{Factors affecting key work outcomes}

Standard multiple regressions were conducted to examine factors that influenced the key work outcomes of emotional exhaustion, mental health and well-being, and job satisfaction. For each outcome, the work factors entered into the model were experiences of racism, work/life imbalance, life/work imbalance, workload, client pressure, co-worker support, positive cultural practices, and work environment (see Table 4).

\subsubsection{Emotional exhaustion}

For Indigenous respondents, work factors accounted for $30 \%$ of variance in levels of emotional exhaustion. The significant predictors of exhaustion were work/family imbalance i.e. work affecting home life and lack of co-worker support. For non-Indigenous respondents, work factors explained $57 \%$ of variance in levels of emotional exhaustion. Work/family imbalance and client pressure were significantly associated with exhaustion.

\subsubsection{Mental health and well-being}

For Indigenous respondents, work factors explained $25 \%$ of the variance in levels of mental health and well-being. Factors that significantly detracted from Indigenous workers' mental health and well-being were family/work imbalance i.e. family life affecting work and experiences of racism. For non-Indigenous respondents, work factors accounted for $35 \%$ of the variance in levels of mental health and well-being. Work/family imbalance and family/work imbalance were significantly associated with poorer mental health and well-being.

Table 3

Mean scores on work factors and work outcomes for respondents.

\begin{tabular}{|c|c|c|c|c|c|c|}
\hline \multirow[t]{2}{*}{ Variable } & \multirow{2}{*}{$\frac{\text { Reliability }}{\alpha}$} & \multirow{2}{*}{$\frac{\text { Score range }}{\text { Low-High }}$} & \multicolumn{2}{|c|}{ Indigenous } & \multicolumn{2}{|c|}{ Non-Indigenous } \\
\hline & & & $n$ & $M(S D)$ & $n$ & $M(S D)$ \\
\hline \multicolumn{7}{|l|}{ Work outcomes } \\
\hline Turnover intention & .77 & $1-5$ & 164 & $2.67(0.89)$ & 94 & $2.75(0.76)$ \\
\hline Emotional exhaustion & .94 & $0-6$ & 170 & $2.23(1.55)$ & 96 & $2.06(1.39)$ \\
\hline Mental health and well-being ${ }^{\mathrm{a}}(p<.001)$ & .78 & $1-3$ & 178 & $2.16(0.42)$ & 102 & $2.41(0.39)$ \\
\hline Job satisfaction & .92 & $1-4$ & 170 & $3.20(0.59)$ & 93 & $3.26(0.51)$ \\
\hline \multicolumn{7}{|l|}{ Work factors } \\
\hline Client pressure & .93 & $1-5$ & 141 & $3.05(1.01)$ & 78 & $3.13(0.80)$ \\
\hline Family/Work imbalance $^{\mathrm{a}}(p<.001)$ & .81 & $1-5$ & 180 & $2.54(0.92)$ & 104 & $2.09(0.61)$ \\
\hline Work/family imbalance ${ }^{\mathrm{a}}(p=.006)$ & .78 & $1-5$ & 180 & $2.96(0.90)$ & 104 & $2.66(0.86)$ \\
\hline Experience of racism & .84 & $1-5$ & 183 & $1.76(0.86)$ & 107 & $1.65(0.65)$ \\
\hline Workload & .45 & $1-5$ & 167 & $3.12(0.87)$ & 95 & $3.15(0.98)$ \\
\hline Positive cultural practices & .80 & $1-5$ & 173 & $3.12(0.80)$ & 93 & $3.05(0.68)$ \\
\hline Co-worker support & .91 & $1-5$ & 182 & $3.71(0.77)$ & 108 & $3.71(0.65)$ \\
\hline Work environment & .74 & $1-5$ & 167 & $3.31(0.97)$ & 93 & $3.31(0.84)$ \\
\hline
\end{tabular}

Note. Higher scores indicate greater level of variables (e.g., high emotional exhaustion, or greater mental health and well-being).

a Mean scores between groups were significantly different. 
Table 4

Standard multiple regression models: Predictor work variables of emotional exhaustion, mental health and well-being, and job satisfaction.

\begin{tabular}{|c|c|c|c|c|c|c|c|c|c|c|c|c|}
\hline \multirow[t]{3}{*}{ Variable } & \multicolumn{4}{|c|}{ Emotional exhaustion } & \multicolumn{4}{|c|}{ Mental health and well-being } & \multicolumn{4}{|c|}{ Job satisfaction } \\
\hline & \multicolumn{2}{|c|}{ Indigenous } & \multicolumn{2}{|c|}{ Non-Indigenous } & \multicolumn{2}{|c|}{ Indigenous } & \multicolumn{2}{|c|}{ Non-Indigenous } & \multicolumn{2}{|c|}{ Indigenous } & \multicolumn{2}{|c|}{ Non-Indigenous } \\
\hline & $B$ & SE & $B$ & $S E$ & $B$ & $S E$ & $B$ & $S E$ & $B$ & $S E$ & $B$ & $S E$ \\
\hline Experience of racism & .160 & .154 & .301 & .170 & $-.088^{* * *}$ & .044 & .027 & .070 & .044 & .061 & -.132 & .102 \\
\hline Work/family imbalance & $.498^{* *}$ & .167 & $.737^{*}$ & .156 & -.086 & .048 & $-.267^{*}$ & .057 & -.093 & .066 & -.079 & .085 \\
\hline Family/work imbalance & .120 & .149 & .173 & .211 & $-.138^{* *}$ & .045 & $-.239^{* *}$ & .078 & -.023 & .059 & .147 & .116 \\
\hline Workload & .131 & .148 & .031 & .125 & -.022 & .043 & .001 & .047 & -.049 & .058 & .093 & .069 \\
\hline Client pressure & .205 & .130 & $.588^{*}$ & .146 & -.058 & .038 & -.062 & .053 & -.025 & .051 & .045 & .080 \\
\hline Co-worker support & $-.467^{* *}$ & .180 & -.359 & .189 & .061 & .053 & .020 & .069 & $.203^{* *}$ & .071 & .136 & .103 \\
\hline Positive cultural practices & .051 & .180 & -.100 & .201 & -.057 & .053 & -.076 & .074 & .046 & .071 & .032 & .111 \\
\hline Work environment & -.203 & .144 & -.100 & .160 & .022 & .042 & -.015 & .059 & .045 & .057 & .016 & .087 \\
\hline Adjusted $R^{2}$ & \multicolumn{2}{|c|}{.295} & \multicolumn{2}{|c|}{.565} & \multicolumn{2}{|c|}{.299} & \multicolumn{2}{|c|}{.348} & \multicolumn{2}{|c|}{.120} & \multicolumn{2}{|c|}{.004} \\
\hline Full model & \multicolumn{2}{|c|}{$F(8,121)=7.76^{*}$} & \multicolumn{2}{|c|}{$F(8,65)=12.85^{*}$} & \multicolumn{2}{|c|}{${ }^{* *} F(8,116)=6.17^{*}$} & \multicolumn{2}{|c|}{$F(8,63)=5.74^{*}$} & \multicolumn{2}{|c|}{$F(8,121)=3.21^{* *}$} & \multicolumn{2}{|c|}{$F(8,64)=1.04$} \\
\hline
\end{tabular}

Note. $B=$ unstandardised coefficient.

$$
\begin{array}{rl}
* & p<.001 . \\
* * & p<.01 . \\
* * * & p<.05
\end{array}
$$

\subsubsection{Job satisfaction}

For Indigenous respondents, work factors explained $12 \%$ of the variance in job satisfaction. Co-worker support was the only factor found to significantly predict job satisfaction. For non-Indigenous respondents, no significant predictors were found to account for job satisfaction.

For both groups, the majority (over 90\%) indicated that achieving successful outcomes for clients, doing work of value to society and having one-to-one interactions with clients were satisfying/very satisfying. Seventy-eight percent $(n=206)$ were "satisfied" or "very satisfied" with opportunities for personal learning or growth and relationships. Just over half of the respondents (i.e., 51\% Indigenous and 57\% non-Indigenous) were satisfied with their salary or benefits. Seventeen percent of Indigenous $(n=29)$ and $10 \%$ of non-Indigenous workers $(n=9)$ indicated that their salary and benefits at work were "not at all satisfying."

\subsubsection{Turnover intention}

The results of the hierarchical regression model for turnover intention are displayed in Table 5. For Indigenous respondents, job satisfaction, mental health and well-being, and emotional exhaustion explained $23 \%$ of variance in turnover intention, with work factors accounting for a further 21\%. Emotional exhaustion and job satisfaction were significant predictors of turnover intention. Of the work factors, poor work environment was significantly associated with turnover intention. Family/Work imbalance and workload significantly predicted turnover intention, but in the opposite direction to what was expected. Further inspection of the correlations between these variables suggested that there were no relationships between workload, family/work imbalance and turnover intention, and that the findings were attributable to statistical artefacts such as suppression effects. This also occurred for client pressure for nonIndigenous respondents.

For non-Indigenous respondents, job satisfaction, mental health and well-being, and emotional exhaustion accounted for $14 \%$ of variance in turnover intention, and work factors accounted for an additional $11 \%$, with a total of $25 \%$ of variance explained by the variables. Emotional exhaustion and a poor work environment contributed to turnover intentions.

For most non-Indigenous respondents, greater recognition or appreciation of effort and more training opportunities were most important for worker retention. Whereas for the majority of nonIndigenous respondents, salary increases and more training opportunities were identified as key retention strategies.

Further post hoc analyses were undertaken to examine potential interaction effects between Indigenous status and key workplace

\begin{tabular}{|c|c|c|c|c|c|c|c|c|}
\hline \multirow[t]{3}{*}{ Variable } & \multicolumn{4}{|c|}{ Indigenous } & \multicolumn{4}{|c|}{ Non-Indigenous } \\
\hline & \multicolumn{2}{|l|}{ Model 1} & \multicolumn{2}{|l|}{ Model 2} & \multicolumn{2}{|c|}{ Model 1} & \multicolumn{2}{|l|}{ Model 2} \\
\hline & $B$ & $S E$ & $B$ & $S E$ & $B$ & $S E$ & $B$ & $S E$ \\
\hline Mental health and well-being & .251 & .211 & .056 & .194 & .144 & .249 & .139 & .269 \\
\hline Emotional exhaustion & $.211^{* *}$ & .060 & $.145^{* *}$ & .055 & $.248^{* *}$ & .077 & $.252^{* * *}$ & .101 \\
\hline Job satisfaction & $-.500^{*}$ & .136 & $-.375^{* *}$ & .124 & .057 & .162 & .123 & .163 \\
\hline Experience of racism & & & -.063 & .082 & & & -.094 & .137 \\
\hline Work/family imbalance & & & .082 & .093 & & & .027 & .129 \\
\hline Family/Work imbalance & & & $.177^{* * *}$ & .084 & & & .115 & .161 \\
\hline Workload & & & $-.183^{* * *}$ & .078 & & & -.006 & .089 \\
\hline Client pressure & & & .018 & .071 & & & $-.263^{* * *}$ & .120 \\
\hline Co-worker support & & & -.003 & .100 & & & -.036 & .134 \\
\hline Positive cultural practices & & & -.160 & .096 & & & -.002 & .141 \\
\hline Work environment & & & $-.426^{*}$ & .077 & & & $-.346^{* *}$ & .111 \\
\hline Adjusted $R^{2}$ & \multicolumn{2}{|c|}{.221} & \multicolumn{2}{|c|}{.434} & \multicolumn{2}{|c|}{.142} & \multicolumn{2}{|c|}{.251} \\
\hline Full model & \multicolumn{2}{|c|}{$F(3,119)=12.54^{*}$} & \multicolumn{2}{|c|}{$F(11,111)=9.52^{*}$} & \multicolumn{2}{|c|}{$F(3,67)=4.85^{* *}$} & \multicolumn{2}{|c|}{$F(11,59)=3.14^{* * *}$} \\
\hline
\end{tabular}

Table 5

Hierarchical multiple regression model: Predictor variables of turnover intention.

Note. $B=$ unstandardised coefficient.

* $p<.001$.

$* * p<.01$.

*** $p<.05$. 
factors for work outcomes. Hierarchical regressions were run with the combined sample, with interaction terms for Indigenous status and the predictor variables that were significant in the previous regressions. No interaction effects were found for indigeneity and emotional exhaustion, mental health and well-being, or job satisfaction. However, for turnover intention, a significant interaction effect was found between Indigenous status and job satisfaction $(F(1,197)=$ $7.32, p=.007)$, and Indigenous status and client pressure $(F(1,197)=$ $5.59, p=.019)$.

\section{Discussion}

This national survey is the first of its kind undertaken to examine workplace health and well-being among Indigenous AOD workers in Australia. Comparison was also made of the experiences of nonIndigenous workers who work in similar settings and who carry out similar functions in terms of providing clinical care and support to Indigenous clients. A range of organisational, workplace and individual factors were examined. Particular emphasis was placed on factors that impact on Indigenous workers' levels of emotional exhaustion, mental health and well-being, job satisfaction, and turnover intentions.

The Indigenous AOD workforce in Australia was found to typically experience above average levels of job satisfaction and relatively low levels of emotional exhaustion. However, nearly twice as many Indigenous workers experienced high levels of exhaustion compared with their non-Indigenous counterparts. Indigenous AOD workers also experienced significantly lower levels of mental health and wellbeing and greater work/family imbalance than their non-Indigenous colleagues. Overall, Indigenous AOD workers were found to face substantial workforce development challenges that impacted upon their health and well-being.

\subsection{Mental health and well-being}

The mental health and emotional well-being of Indigenous respondents was significantly lower on average than non-Indigenous respondents. Indigenous respondents tended to worry more and feel restless, and were regularly affected by past family events. In the qualitative component of this project (Roche et al., 2010), loss and grief issues featured prominently in Indigenous AOD workers' depiction of stress factors. While having dependents was significantly associated with better mental health and well-being for nonIndigenous respondents, this was not the case for Indigenous respondents. Although data were not obtained on the number of dependents, it is likely that non-Indigenous workers had substantially fewer dependents than Indigenous workers. Further, Indigenous respondents reported higher levels of life/work imbalance (i.e., family life affecting work) on average, compared with non-Indigenous respondents. Factors that significantly predicted Indigenous respondents' poorer levels of mental health and well-being were life/work imbalance, as well as experiences of racism.

Even though low levels of racism were reported by the current sample, it is a significant factor in Indigenous workers' mental health. A recent study of Aboriginal and Torres Strait Islander health found that regularly experiencing racism was associated with poor mental health (Gallaher et al., 2009). As identified in the qualitative component of this project, survey respondents may have been wary about raising issues related to racism.

From an Indigenous perspective, issues pertaining to health and well-being are systemic and connected to the land, spirituality, culture, ancestry, family and community (South Australian Aboriginal Health Partnership, 2005). In light of the breadth of issues faced by Indigenous workers, a more holistic approach to addressing Indigenous AOD workers' health and well-being may be required with consideration given towards the broader family and community context (MCDS, 2006). An example of this would be to offer flexible employment arrangements that allow workers' familial, cultural and social obligations to be met so that they could successfully balance their work, family and community commitments.

\subsection{Employment conditions}

Indigenous workers reported lower salaries than non-Indigenous workers, and were less than half as likely to earn more than $\$ 60,000$ compared with non-Indigenous workers, even after controlling for age, drug- and alcohol-specific qualifications, hours worked, and type of shifts worked. The salary disparity may be due in part to respondents' occupations and educational qualifications: non-Indigenous workers were more likely to be AOD workers and nurses, with a higher level of education, while Indigenous workers were more likely to be Aboriginal/Islander health workers with vocational education qualifications or lower. Respondents who were Aboriginal/Islander health workers were significantly more likely to have lower wages than respondents in other occupational groups. In a comparison of 12 selected community service occupations by the Australian Services Union (Australian Services Union, 2007), Aboriginal Health Workers received the lowest average weekly pay (\$547.76). Proportionally more Indigenous workers also indicated that their salaries and benefits were the least satisfactory aspect of their work. The majority of Indigenous workers in the sample also listed salary increases as the most important retention strategy.

The high level of unpaid overtime reported is a source of concern. While indicative of Indigenous AOD workers' commitment to their community, unpaid overtime is also likely to contribute to higher levels of work/life imbalance, a predictor of burnout. The high level of unpaid overtime could also reflect insufficient staff to meet client demand. Nearly half the respondents indicated staff shortages at their workplace which affected their capacity to provide quality services and approximately $40 \%$ felt too much was expected of all staff. This is consistent with a recent Canadian study which found that jobs requiring extra working hours or variable hours are associated with high work stress (Dewa, Thompson, \& Jacobs, 2011).

These reported employment conditions mirror the workforce challenges and issues faced by the Indigenous health workforce at large (AIHW, 2009a, 2009b; Pink, 2008).

\subsection{Emotional exhaustion}

Somewhat unexpectedly, Indigenous respondents' levels of emotional exhaustion were moderate to low on average. Nonetheless, more than 1 in 10 Indigenous respondents experienced very high levels of emotional exhaustion, which is a major indication of burnout, compared with $6 \%$ of non-Indigenous respondents. Work/Life imbalance (work affecting home life) and lack of co-worker support were critical factors in predicting burnout. While Indigenous workers reported greater work/life imbalance they also reported high levels of co-worker support which may be effective in ameliorating workrelated strain. As other studies have found (e.g., Ducharme, Knudsen, \& Roman, 2007), co-worker support appears to mitigate against stress and burnout, and in addressing vicarious trauma and emotional fatigue (Fahy, 2007) among drug and alcohol workers.

The comparatively lower amount of variance explained in burnout for Indigenous workers suggests a more complex array of factors may be at play beyond those addressed in this survey, such as community expectations and obligations faced by an Indigenous worker. As identified in the qualitative component of this project, Indigenous workers are confronted with high expectations from their communities and a strong cultural obligation exists to meet these expectations, which can contribute to stress and exhaustion (Roche et al., 2010). To fully examine the factors that predict burnout for 
Indigenous workers, a more nuanced and comprehensive coverage of potential contributory factors is required.

For non-Indigenous workers, work/life imbalance and client pressure were predictive of burnout levels. Non-Indigenous workers reported experiencing pressure from different types of clients, particularly manipulative, poly-drug using, and demanding clients. Greater training and support in the form of clinical supervision (Knudsen, Ducharme, \& Roman, 2008; Roche, Todd, \& O'Connor, 2007; Health Workforce Australia, 2010) may help workers manage pressures they face from difficult clients.

\subsection{Job satisfaction}

Consistent with previous Australian (Duraisingam et al., 2006, 2007) and international studies (Faragher, Cass, \& Cooper, 2005; Ogborne \& Graves, 2005), the current sample reported high levels of satisfaction with their jobs. While only half the respondents found salary and benefits to be satisfying, a substantial majority found more altruistic aspects of the job to be most satisfying. These included achieving successful outcomes for clients, doing work of value to society, and one-on-one interactions with clients. These aspects of satisfaction also featured prominently in other studies of AOD workers in Australia, and the US (e.g., Duraisingam et al., 2006, 2007; Evans \& Hohenshil, 1997). One in five Indigenous workers, and 1 in 10 non-Indigenous workers, reported dissatisfaction with their salary and benefits at work. Support from co-workers was also an important factor that contributed to job satisfaction, particularly among Indigenous workers.

While most Indigenous AOD workers are intrinsically motivated to achieve successful client and societal outcomes, it is also essential to ensure that extrinsic rewards of salary and benefits are equitably available to all workers. This is crucial to maintain job satisfaction and attract and retain workers in the field.

\subsection{Turnover and retention}

More Indigenous respondents reported shorter lengths of service in their current organisation compared with non-Indigenous respondents, which may indicate greater turnover and/or more recent recruitment initiatives. Nearly half the respondents from both groups had been employed in their organisation for 2 years or less. This implies either higher turnover among AOD workers within Indigenous AOD organisations, which is an issue of concern, or an encouraging increase in recruitment rates.

Indigenous respondents' turnover intentions were typically slightly above average. Female Indigenous respondents had higher turnover intention scores compared with their male counterparts. As found in previous research (Duraisingam et al., 2006, 2007; Ducharme et al., 2007; Knudsen et al., 2009), high levels of emotional exhaustion was a key predictor of Indigenous respondents' intention to leave their job. Other significant predictors were low levels of job satisfaction, and a negative perception of the work environment, consistent with other studies that have highlighted the importance of procedural and distributive justice in the workplace (Rothrauff, Abraham, Bride, \& Roman, 2011).

In relation to retention, salary increases and more training opportunities were pivotal retention strategies for Indigenous respondents. Non-Indigenous respondents noted that more recognition/appreciation of effort and more training opportunities were most important for promoting worker retention. Another valued retention strategy for both groups was a more supportive workplace. Indigenous workers also highlighted career opportunities as a central strategy to improve retention, whereas non-Indigenous respondents nominated reduced administrative workloads as a key retention strategy. For Indigenous workers and the employment categories they occupy maximising the creation of career pathways, that are largely absent at present, was a priority.

While funding issues may limit the capacity of individual organisations to address salary levels and associated satisfaction and pay equity in the short term, they can easily implement strategies to provide greater recognition and appreciation of effort and foster more supportive workplace environments. However, long term measures including increasing opportunities for professional development and growth and addressing the wage disparities between Indigenous and non-Indigenous workers in the AOD field are also needed.

The identification of interaction effects for turnover intention, between Indigenous status and job satisfaction and also client pressure, may indicate that for Indigenous and non-Indigenous workers these factors carry different levels of importance. More research is required to examine this further as the salience of certain workplace factors that impact on job satisfaction and perception of pressure may be different for Indigenous and nonIndigenous workers.

\subsection{Workforce representation}

Indigenous survey respondents were typically female, and younger on average than non-Indigenous respondents. The high proportion (70\%) of female respondents was consistent with Indigenous health workforce and national AOD workforce data (AIHW, 2007; Duraisingam et al., 2006; Roche, 2008; Roche, O'Neill, \& Wolinksi, 2004; Wolinski et al., 2003). The comparatively younger age of Indigenous respondents may be an encouraging indication that the Indigenous AOD field is attracting new, young workers and expanding the Indigenous AOD workforce. Conversely, there were proportionally fewer mature-age Indigenous workers. This suggests that younger Indigenous AOD workers may lack support and guidance from older, more experienced workers who can act as mentors, role models and advocates. This finding may be further compounded in Indigenous workplaces where the workplace culture is less familiar with supervision (Gray et al., 2004). Previous research has demonstrated the importance of clinical supervision in minimising emotional exhaustion and turnover in AOD workers (Knudsen et al., 2008; Roche et al., 2007).

Based on the distribution of the Indigenous health workforce population (AIHW, 2009a, 2009b) the survey sample appeared to be representative in terms of geographic location (metropolitan/ non-metropolitan) and organisational sector (government/nongovernment). No other demographic data were available for comparison purposes.

\subsection{Limitations}

There were several limitations to the study. Firstly, the use of cross-sectional data precludes conclusions being drawn regarding causal relationships. Secondly, convenience sampling was adopted to maximise the sample size but prevents calculation of a response rate. A random sampling strategy was not possible. Although the Australian Indigenous workforce is large it is not well-defined, and established sampling frames do not yet exist. Thirdly, a non-response bias may have influenced the results. A face-to-face approach is generally viewed as a more effective strategy to collect accurate data when conducting research with Indigenous Australians but was beyond available resources. Given the small sample size, further studies are warranted to examine the associations between the work factors and outcomes measured in this study.

\subsection{Conclusions}

This study is the first national examination of Indigenous AOD worker well-being. While many positive findings were identified in 
terms of the satisfaction workers derived from their roles in supporting their community it was clear that it was often at the expense of their own physical and mental health and well-being. The findings highlight the need for improved organisational support, better salaries and working conditions, enhanced career paths and overall support. It also underscores the importance of taking a holistic approach to workforce development for Indigenous workers and ensuring that the broader family and community context is included when addressing Indigenous AOD worker well-being, as the concept of health and well-being from an Indigenous perspective takes into account not only the individual but also their community and surrounding environment. Implementation of the range of workplace improvements highlighted in this study may increase job satisfaction and thereby reduce turnover intention among Indigenous workers.

\section{Acknowledgements}

This study was funded by the Australian Government Department of Health and Ageing. The authors would like to acknowledge the support of the Project Reference Group and the frontline AOD workers who participated in the survey. Thanks are also extended to the other members of NCETA's Project Team, Ms Donna Weetra and Ms Tania Steenson. The advice of Dr Toby Freeman and Dr Ken Pidd on the data analyses is gratefully acknowledged, as is Mr Brian Marshall for his contribution to the development of the survey.

\section{References}

AHMAC. (2004). Cultural respect framework for Aboriginal and Torres Strait Islander Health 2004-2009. Adelaide: Department of Health South Australia. Australian Health Ministers' Advisory Council.

AIHW. (2007). Aboriginal and Torres Strait Islander health performance framework, 2006 report: Detailed analyses (No. 20). Canberra: Australian Institute of Health and Welfare (AIHW)

AIHW. (2008). 2007 National Drug Strategy Household Survey: Detailed findings (No. 107). Canberra: Australian Institute of Health and Welfare (AIHW).

AIHW. (2009). Aboriginal and Torres Strait Islander health labour force statistics and data quality assessment. Canberra: Australian Institute of Health and Welfare (AIHW).

AIHW. (2009). Aboriginal and Torres Strait Islander health labour force statistics and data quality assessment (No. 27). Canberra: Australian Institute of Health and Welfare (AIHW).

AIHW. (2010). Australia's health 2010 (No. AUS 122). Canberra: Australian Institute of Health and Welfare (AIHW).

Australian Government Department of Health and Ageing. (2008). Report on the audit of the health workforce in rural and regional Australia, April 2008. Canberra, ACT: Commonwealth of Australia.

Australian Services Union. (2007). Building social inclusion in Australia: Priorities for the social and community services sector workforce. Melbourne, Victoria: Australian Services Union.

Dewa, C. S., Thompson, A. H., \& Jacobs, P. (2011). Relationships job stress and worker perceived responsibilities and job characteristics. International Journal of Occupational and Environmental Medicine, 2, 37-46.

Ducharme, L. J., Knudsen, H. K., \& Roman, P. M. (2007). Emotional exhaustion and turnover intention in human service occupations: The protective role of co-worker support. Sociological Spectrum, 28, 81-104.

Duraisingam, V., Pidd, K., Roche, A. M., \& O'Connor, J. (2006). Satisfaction, stress and retention among alcohol \& other drug workers in Australia. Adelaide: National Centre for Education and Training on Addiction (NCETA), Flinders University.

Duraisingam, V., Roche, A. M., Pidd, K., Zoontjens, A., \& Pollard, Y. (2007). Wellbeing stress and burnout: A national survey of managers in alcohol and other drug treatment services. Adelaide: National Centre for Education and Training on Addiction (NCETA), Flinders University.

Evans, W. N., \& Hohenshil, T. H. (1997). Job satisfaction of substance abuse counselors. Alcoholism Treatment Quarterly, 15, 1-13.

Fahy, A. (2007). The unbearable fatigue of compassion: Notes from a substance abuse counselor who dreams of working at Starbuck's. Clinical Social Work Journal, 35, 199-205.

Faragher, E. B., Cass, M., \& Cooper, C. L. (2005). The relationship between job satisfaction and health: A meta-analysis. Occupational and Environmental Medicine, 62, $105-112$.

Farmer, R., Clancy, C., Oyefeso, A., \& Rassool, G. H. (2002). Stress and work with substance misusers: The development and cross-validation of a new instrument to measure staff stress. Drugs: Education, Prevention and Policy, 9, 377-388.

Gallaher, G., Ziersch, A., Baum, F., Bentley, M., Palmer, C., Edmondson, W., et al. (2009). In our own backyard: Urban health inequities and Aboriginal experiences of neighbourhood life, social capital and racism. Adelaide: Flinders University.
Genat, B., Bushby, S., McGuire, M., Taylor, E., Walley, Y., \& Weston, T. (2006). Aboriginal health workers: Primary health care at the margins. University of Western Australia Press.

Gray, D., Saggers, S., Atkinson, D., \& Strempel, P. (2004). Substance misuse and primary health care among Indigenous Australians. Perth: Office of Aboriginal and Torres Strait Islander Health.

Guerin, B., Guerin, P. B., \& Seamann, K. (2011). Seeds of sustainability: Growing your desert communities. Alice Springs: Ninti One Limited.

Health Workforce Australia (2010). Clinical Supervisor Support Program-Discussion paper, July 2010. Adelaide: Health Workforce Australia.

Knudsen, H. K., Ducharme, L. J., \& Roman, P. M. (2006). Counselor emotional exhaustion and turnover intention in therapeutic communities. Journal of Substance Abuse Treatment, 31, 173-180.

Knudsen, H. K., Ducharme, L. J., \& Roman, P. M. (2008). Clinical supervision, emotional exhaustion and turnover intention: A study of substance abuse treatment counselors in the Clinical Trial Network of the National Institute on Drug Abuse. Journal of Substance Abuse Treatment, 35, 387-395.

Knudsen, H. K., Ducharme, L. J., \& Roman, P. M. (2009). Turnover intention and emotional exhaustion "at the top": Adapting the job demands-resources model to leaders of addiction treatment organizations. Journal of Occupational Health Psychology, 14, 84-95.

Ladd, D., \& Henry, R. A. (2000). Helping coworkers and helping the organization: The role of support perceptions, exchange ideology, and conscientiousness. Journal of Applied Psychology, 30, 2028-2049.

Maslach, C., Jackson, S. E., \& Leiter, M. P. (1996). Maslach Burnout Inventory manual (3rd ed.). Palo Alto, CA: Consulting Psychological Press.

Maslach, C., Schaufeli, W. B., \& Leiter, M. P. (2001). Job burnout. Annual Review of Psychology, 52, 397-422.

MCDS. (2006). National drug strategy: Aboriginal and Torres Strait Islander peoples complementary action plan 2003-2009. Background paper. Canberra, ACT: Ministerial Council on Drug Strategy (MCDS).

O'Driscoll, M. P., \& Beehr, T. A. (1994). Supervisor behaviours, role stressors and uncertainty as predictors of personal outcomes for subordinates. Journal of Organizational Behavior, 15, 141-155.

Ogborne, A. C., \& Graves, G. (2005). Optimizing Canada's addiction treatment workforce: Results of a national survey of service providers. Ottawa, ON: Canadian Centre on Substance Abuse.

Oyefeso, A., Clancy, C., \& Farmer, R. (2008). Prevalence and associated factors in burnout and psychological morbidity among substance misuse professionals. BMC Health Services Research, 8.

Panaretto, K. S., \& Wenitong, M. (2006). The general practitioner. Medical Journal of Australia, 184, 527-528.

Pink, B. (2008). Labour force characteristics of Aboriginal and Torres Strait Islander Australians. Estimates from the Labour Force Survey, 2007. Canberra: Australian Bureau of Statistics.

Pitts, J. A. (2001). Identifying workforce issues within the alcohol and other drugs sector: Responses to a national survey. In A. M. Roche, \& J. McDonald (Eds.), Systems, settings and people: Workforce development challenges for the alcohol and other drugs field (pp. 31-36). Adelaide: National Centre for Education and Training on Addiction (NCETA), Flinders University.

Pocock, B., Williams, P., \& Skinner, N. (2007). The Australian Work and Life Index (AWALI): Concepts, methodology and rationale (Discussion Paper No. 1/07). Adelaide: Centre for Work and Life, University of South Australia.

Price, J. L., \& Mueller, C. W. (1981). Professional turnover: The case of nurses. New York: Spectrum

Roche, A. M. (2008). How many AOD workers are there? Of Substance, 6, 26

Roche, A. M., Duraisingam, V., Wang, P., \& Tovell, A. (2008). Alcohol and other drugs, mental health and comorbidity: A training review. Adelaide, South Australia: National Centre for Education \& Training on Addiction, Flinders University.

Roche, A. M., O'Neill, M., \& Wolinksi, K. (2004). Alcohol and other drug specialist treatment services and their managers: Findings from a national survey. Australia and New Zealand Journal of Public Health, 28, 252-258.

Roche, A. M., \& Pidd, K. (2010). Alcohol E' other drugs workforce development issues and imperatives: Setting the scene. Adelaide: National Centre for Education and Training on Addiction (NCETA), Flinders University

Roche, A. M., Todd, C., \& O'Connor, J. (2007). Clinical supervision in the alcohol and other drugs field: An imperative or an option? Drug and Alcohol Review, 26 313-321.

Roche, A. M., Tovell, A., Weetra, D., Freeman, T., Bates, N., Trifonoff, A., et al. (2010). Stories of resilience: Indigenous alcohol and other drug workers' wellbeing, stress and burnout. Adelaide: National Centre and Training on Addiction (NCETA), Flinders University.

Rothrauff, T. C., Abraham, A. J., Bride, B. E., \& Roman, P. M. (2011). Occupational turnover intentions among substance abuse counsellors. Journal of Substance Abuse Treatment, 40, 67-76.

Schlesinger, C. M., Ober, C., McCarthy, M. M., Watson, J. D., \& Seinen, A. (2007). The development and validation of the Indigenous Risk Impact Screen (IRIS): A 13-item screening instrument for alcohol and drug and mental health risk. Drug and Alcohol Review, 26, 109-117.

Shakeshaft, A., Clifford, A., \& Shakeshaft, M. (2010). Reducing alcohol-related harm experienced by Indigenous Australians: Identifying opportunities for Indigenous primary health care services. Australian and New Zealand Journal of Public Health, 34(Special Issue), S41-S45.

South Australian Aboriginal Health Partnership. (2005). Aboriginal health, everybody's business: Knowing the business: Social and emotional wellbeing: A South Australian 
strategy for Aboriginal \& Torres Strait Islander people 2005-2010. Adelaide, SA: SAAHP.

Stanley, J., Tomison, A. M., \& Pocock, J. (2003). Child abuse and neglect in Indigenous Australian communities. Child Abuse Prevention Issues.

Strempel, P., Saggers, S., Gray, D., \& Stearne, A. (2004). Indigenous drug and alcohol projects: Elements of best practice. Canberra: Australian National Council on Drugs (ANCD).
Taylor, K., \& Guerin, P. (2010). Health care and Indigenous Australians: Cultural safety in practice. Melbourne: Palgrave Macmillan.

Wilson, M., Stearne, A., Gray, D., \& Saggers, S. (2010). The harmful use of alcohol amongst Indigenous Australians. Australian Indigenous HealthInfoNet.

Wolinski, K., O'Neill, M., Roche, A. M., Freeman, T., \& Donald, A. (2003). Alcohol and other drug treatment agencies: A national workforce development survey. Adelaide: National Centre for Education and Training on Addiction (NCETA), Flinders University. 